\title{
CHALLENGES OF USING ELEMENTAL NICKEL AND TITANIUM POWDERS FOR THE FABRICATION OF MONOLITHIC NiTi PARTS
}

\begin{abstract}
Due to its interesting properties and wide applications in different industries, fabrication of monolithic NiTi with cost-effective methods is an important and attractive issue. One of the economic ways to fabricate NiTi is employing elemental nickel and titanium powders. In this study, effects of using elemental powders as a precursor on the microstructure and mechanical properties of HIP-consolidated NiTi samples will be explored. The result of XRD analysis showed that after HIP process an interwoven structure which consists of $\mathrm{NiTi}_{2}, \mathrm{Ni}_{3} \mathrm{Ti}$ and B2-B19' $\mathrm{NiTi}$ evolves. The formation of $\mathrm{NiTi}_{2} / \mathrm{Ni}_{3}$ Ti intermetallics is thermodynamically favored which affects different aspects of this alloy: (i) it alters martensitic transformation temperatures; (ii) restricts essential properties of this alloy such as PE and SME, (iii) increases hardness, and (iv) yields to premature fracture at small strains during tensile tests.

Keywords: NiTi, mechanical alloying, hot isostatic pressing, microstructure, mechanical properties
\end{abstract}

\section{Introduction}

Near equiatomic NiTi alloys have been extensively used in various industrial and biomedical applications [1-3]. Most of the unique properties of this alloy such as shape memory effect (SME) and pseudoelasticity (PE) originate from its martensitic transformation which occurs with the shear mechanism between the high temperature B2 phase (austenite) and the low temperature B19' (martensite) phase [4]. According to the thermoelastic nature of the martensitic transformation in NiTi, many factors such as Ni/Ti ratio and internal / external stresses can affect this transformation, and, as a consequence, alter the final product properties [4-7].

Several methods have been proposed for the manufacturing of nitinol which can be categorized in two main groups: (1) casting-based methods such as VIM (Vacuum Arc Remelting), VIR (Vacuum Induction Melting) and EBM (Electron Beam Melting), and (2) powder metallurgy (PM)-based methods such as HIP (Hot Isostatic Pressing), and SPS (Spark Plasma Sintering) [3,7].

One of the main obstacles to wide-spread commercializing of NiTi is its poor machinability which limits the fabrication of specimens with complicated geometries. Also, the segregation and microstructural inhomogenity of final products in casting methods can negatively affect the properties of NiTi [8].

Due to above mentioned problems, using of PM methods are favored recently. In powder metallurgy-based methods, the characteristics of starting powders such as particle size and particle shape have a great influence on the properties of final consolidated products. In PM-based methods, two kinds of starting materials can be used as a feedstock for production of NiTi: (i) elemental high-purity nickel and titanium powders which were mixed with a high energy ball mill, and (2) prealloyed Nitinol powder which prepared by using a gas atomization method [9].

Manufacturing of industrial products with a lower price is a very important issue. Several studies have been focused on the production of cost-effective NiTi parts with using elemental Ni-Ti powders. However, using of elemental powders instead of prealloyed NiTi powder can be challenging. In this study, the challenges of using elemental powders instead of prealloyed powder for production of NiTi samples will be investigated. According to low sinterability of NiTi samples, hot isostatic pressing method was used for sintering process.

\section{Experimental}

To fabricate equiatomic NiTi samples ( $\mathrm{Ti}-50 \mathrm{Ni}$ (at.\%)), nickel powder with the purity of $99.8 \%$ (INCO Company, Canada) and titanium powder with the purity of $99.6 \%$ (Alfa Aesar, Germany) were used (Fig. 1). After weighing of starting powders, they were mechanically alloyed (MA) under argon atmosphere with a high energy planetary ball mill at a rotational speed of $300 \mathrm{rpm}$ and ball to powder ratio of 10/1, according to procedure described in Ref. [10]. The mixed powders have been hot-isostatically-pressed at pressure of $100 \mathrm{MPa}$ for $3 \mathrm{~h}$ at temperature of $1065^{\circ} \mathrm{C}[5,11]$. The HIP-processed samples were

\footnotetext{
CERAMIC DIVISION, MATERIALS AND ENERGY RESEARCH CENTER, P.O. BOX 14155-4777, TEHRAN, IRAN

Corresponding author: mmfarvizi@yahoo.com,mmfarvizi@merc.ac.ir
} 
mechanically polished to a 2000 grit $\mathrm{SiC}$ finish. A D8 advanced Bruker diffractometer with $\mathrm{Cu} \mathrm{K} \alpha$ radiation was used to examine the phase constituents of samples.

The microstructure and chemical composition of powders and consolidated samples were studied using an energy dispersive $\mathrm{x}$-ray (EDX) equipped scanning electron microscopy (SEM: JSPM-5400, JEOL, Japan). The martensitic transformation temperatures of HIP-processed samples were determined by using a Mettler-Toledo differential scanning calorimetry (DSC).

Tensile tests were performed on dog-bone-type samples ( $0.6 \mathrm{~mm}$ thick, width of $0.7 \mathrm{~mm}$ and gage length of $1.5 \mathrm{~mm}$ ) using an Instron 8862 machine (INSTRON, Norwood, MA, USA) at room temperature $\left(23^{\circ} \mathrm{C}\right)$. The initial strain rate was $1.0 \times 10^{-3} \mathrm{~s}^{-1}$ during all tests. An optical strain gauge system (ARAMIS 5M) was used during tensile tests to reach accurate strain values.

Local mechanical properties of consolidated samples were calculated by using nanoindentation technique (Agilent Technologies Nanoindenter 6200) with a three-sided Berkovich tip. At

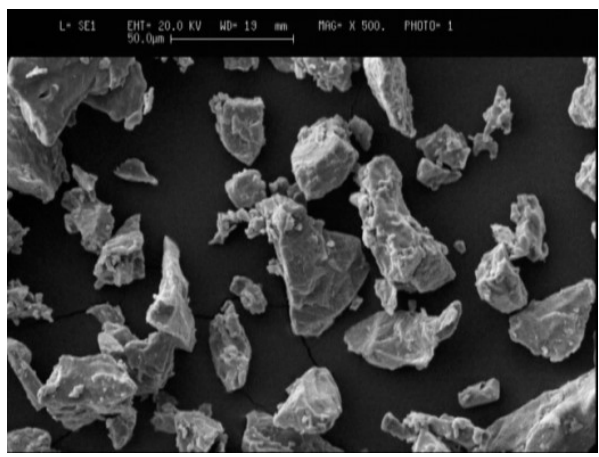

(a)

Fig. 1. SEM images of the starting powders (a) nickel and (b) titanium

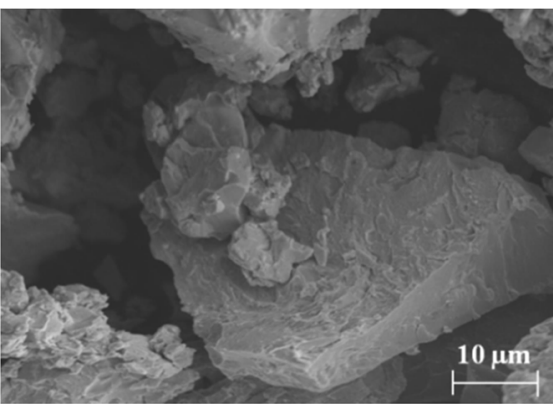

(a)

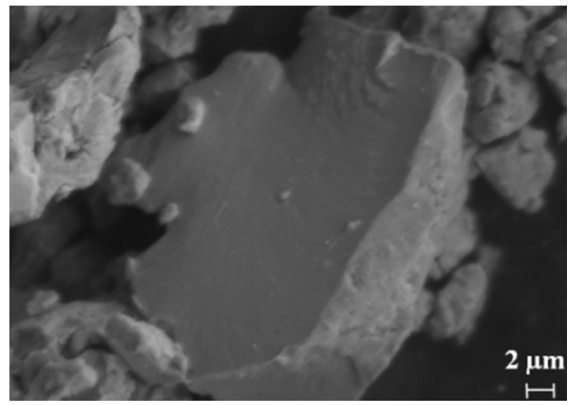

(c) least ten indentations were conducted on each sample. The $\eta$ ratio which is a measure of pseudoelasticity was calculated according to the method proposed in Ref. [12].

\section{Results and discussion}

\subsection{Mechanical milling of $\mathrm{Ni}-\mathrm{Ti}$}

In this study, high purity elemental $\mathrm{Ni}$ and Ti powders were used to prepare NiTi samples. In mechanical alloying process, due to continuous collisions between the grinding media and powders, severe deformation can be induced which can change the morphology of powders [13]. Because of the nature of the starting powders, the mechanical alloying of Ni-Ti lies in ductileductile category. During MA of Ni-Ti, first, due to collisions in vial and cold welding process, a lamellar structure forms (Fig. 2a). With increasing the milling time, lamellar particles

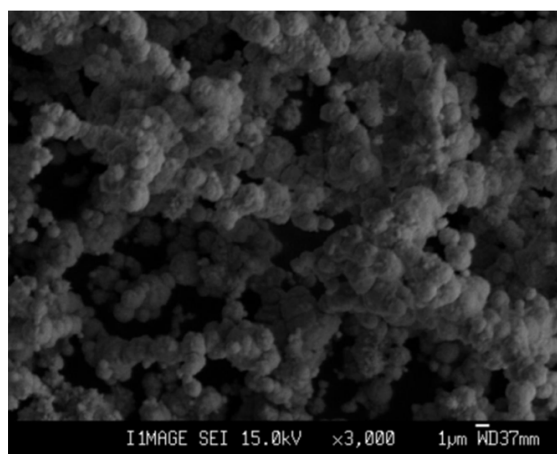

(b)

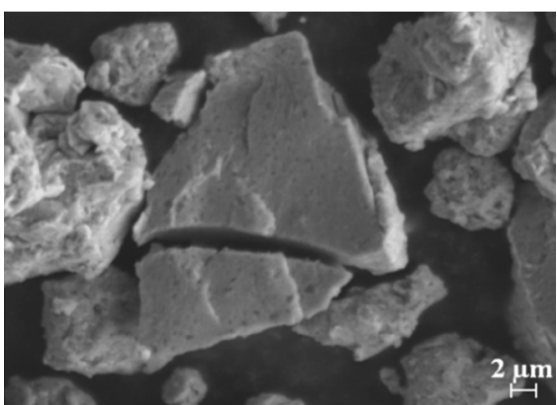

(b)

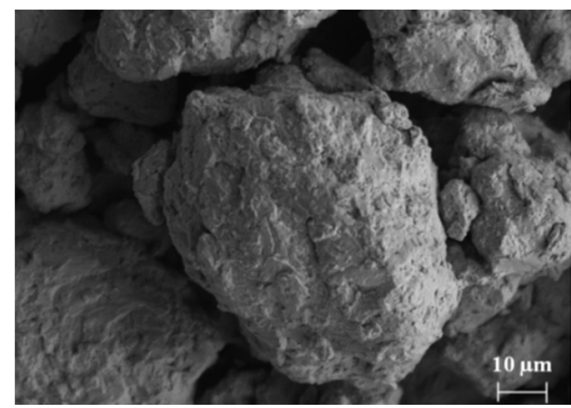

(d)

Fig. 2. Different stages of mechanical alloying in Ni-Ti system until reaching steady-state condition, (a) formation of lamellar structure, (b) fracture of lamellar particles, (c) formation of oxide-free surfaces, and (d) formation of equiaxed morphology 
start to fracture (Fig. 2b) and, simultaneously, the grain size of particles reduces. Due to fracturing of lamellar particles, clean and oxide-free surfaces can be produced (Fig. 2c). Also, the number of structural defects increases with the milling time. These factors can considerably help the alloying process [13]. The cold-welding and fracturing processes repeatedly occur, and consequently after milling of Ni-Ti powders for $50 \mathrm{~h}$, powders reaches a steady state with equiaxed morphology (Fig. 2d).

The results of XRD analysis performed on the MA-processed powders (Fig. 3) show that with increasing the milling time and with start and continuation the alloying process, the intensity of peaks related to initial $\mathrm{Ti}$ and $\mathrm{Ni}$ elements decreases. After $30 \mathrm{~h}$ of milling, these peaks completely disappear and after $50 \mathrm{~h}$ milling, new peaks related to B2-NiTi at $2 \theta=42.8^{\circ}$ and $61.9^{\circ}$ forms.

\subsection{Consolidation of MA-processed Ni-Ti powders with HIP method}

The precursor powders produced by MA were hot isostatically pressed to fabricate monolithic NiTi samples. The results of density measurements with Archimedes method showed that the density of sintered samples have reached to higher than $98 \%$ of their theoretical values.

The XRD pattern (Fig. 4a) of HIP-processed NiTi sample which prepared from mechanically alloyed elemental $\mathrm{Ni}$ and $\mathrm{Ti}$ powders show that after sintering process, $\mathrm{Ni}$-rich $\left(\mathrm{Ni}_{3} \mathrm{Ti}\right)$, Ti-rich $\left(\mathrm{NiTi}_{2}\right)$ and B2/B19' NiTi phases coexist in the sintered sample. The SEM observation of the microstructure of this sample (Fig. 4b) also confirmed the formation of an interwoven structure. In this image, $\mathrm{Ni}_{3} \mathrm{Ti}$ (brighter phase), $\mathrm{NiTi}_{2}$ (darker phase) and NiTi phases can be easily distinguished. The Gibbs free energy of formation of phases $(\Delta \mathrm{G})$ is the key factor which determines the stability of phases during sintering. According to the data presented in references $[14,15]$, at temperature of $1065^{\circ} \mathrm{C}$ in which

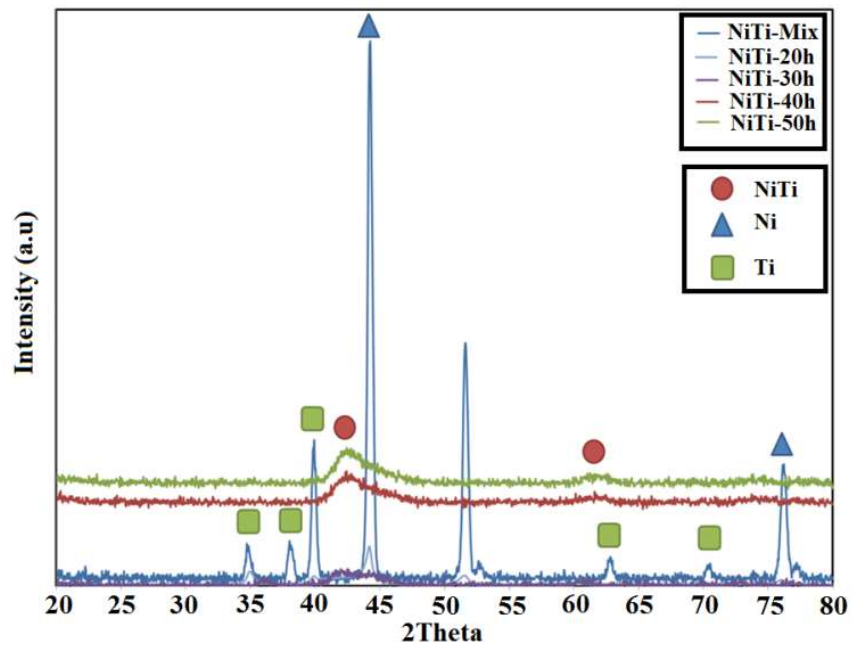

Fig. 3. XRD patterns of Ni-Ti powders after mechanical alloying until $50 \mathrm{~h}[10]$

HIP process conducted, both of $\mathrm{Ni}_{3} \mathrm{Ti}$ and $\mathrm{NiTi}_{2}$ intermetallics have lower $\Delta G^{0}$ than NiTi phase which yields to the formation of these intermetallics.

Formation of $\mathrm{NiTi}_{2} / \mathrm{Ni}_{3} \mathrm{Ti}$ phases can considerably affect NiTi properties. One of the most important aspects of NiTi alloy is its martensitic transformation. Previous researches $[4,16]$ (Fig. 5) have shown that the temperature at which martensitic transformation starts $\left(\mathrm{M}_{\mathrm{s}}\right)$ is extremely sensitive to chemical composition of NiTi (Ni/Ti ratio). Formation of Ni-rich and Ti-rich intermetallics can completely change the transformation temperatures and, as a consequence, makes hard to design an alloy with desired martensite start and finish temperatures. Also, formation of stable intermetallics reduces the volume fraction of NiTi in the sintered samples which leads to the reduction of latent heat of martensitic transformation. The magnitude of this latent heat shows the amount of NiTi which can participate in martensitic transformation.
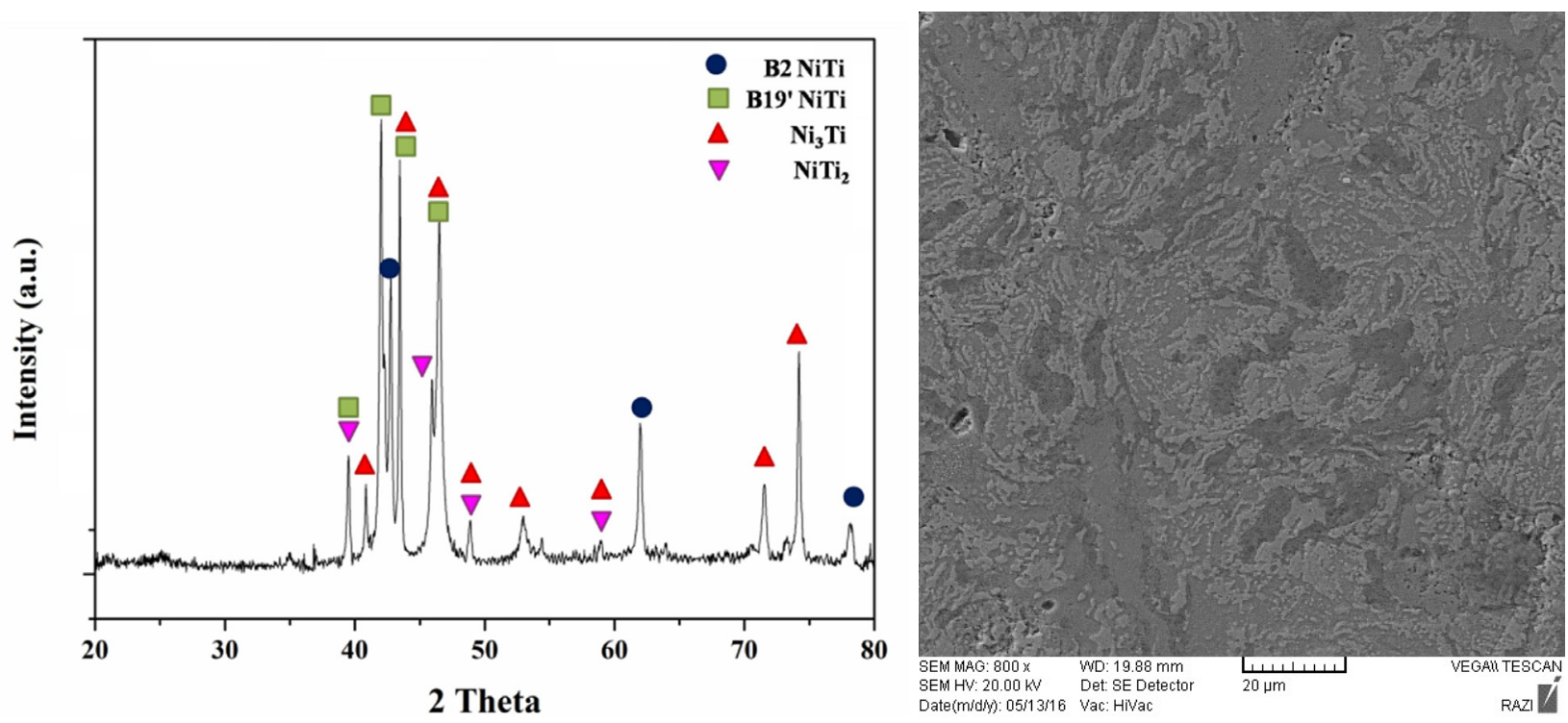

Fig. 4. (a) XRD pattern, and (b) SEM micrograph of HIP-consolidated sample prepared from Ni-Ti MA powders milled for $50 \mathrm{~h}$ 


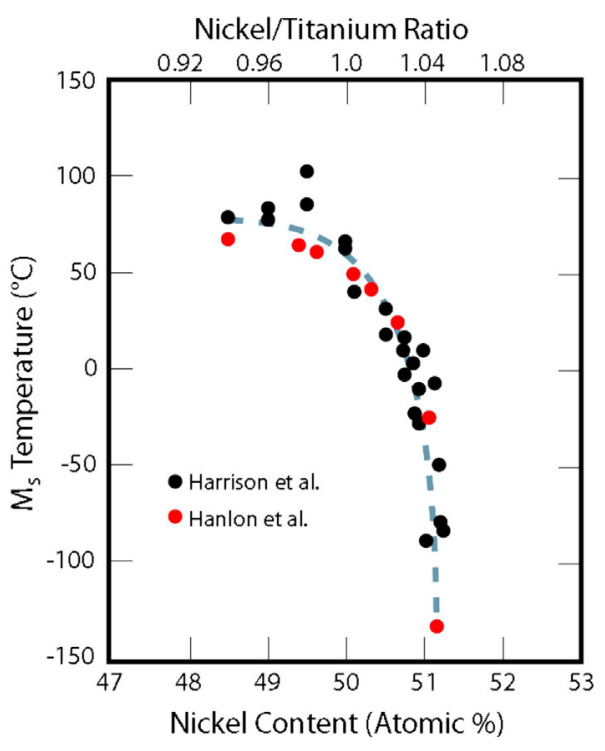

Fig. 5. Effect of chemical composition of NiTi on martensite start temperature $[4,16]$

\subsection{Effect of stable intermetallics on mechanical properties of NiTi}

Another effect of $\mathrm{NiTi}_{2} / \mathrm{Ni}_{3} \mathrm{Ti}$ formation is its influence on mechanical properties of sintered samples. In Fig. 6, the results of tensile tests performed on equiatomic NiTi which prepared from both elemental powders and prealloyed powders with similar composition have been presented. It is seen that the sample which prepared from prealloyed NiTi powder (free of stable intermetallics) shows the common four stages behavior during the deformation which confirms the possibility of detwinning and/ or stress induced martensite formation processes in this sample [17]. However, the sample which prepared from mechanically alloyed $\mathrm{Ni}$-Ti powders did not perform satisfactory during tensile

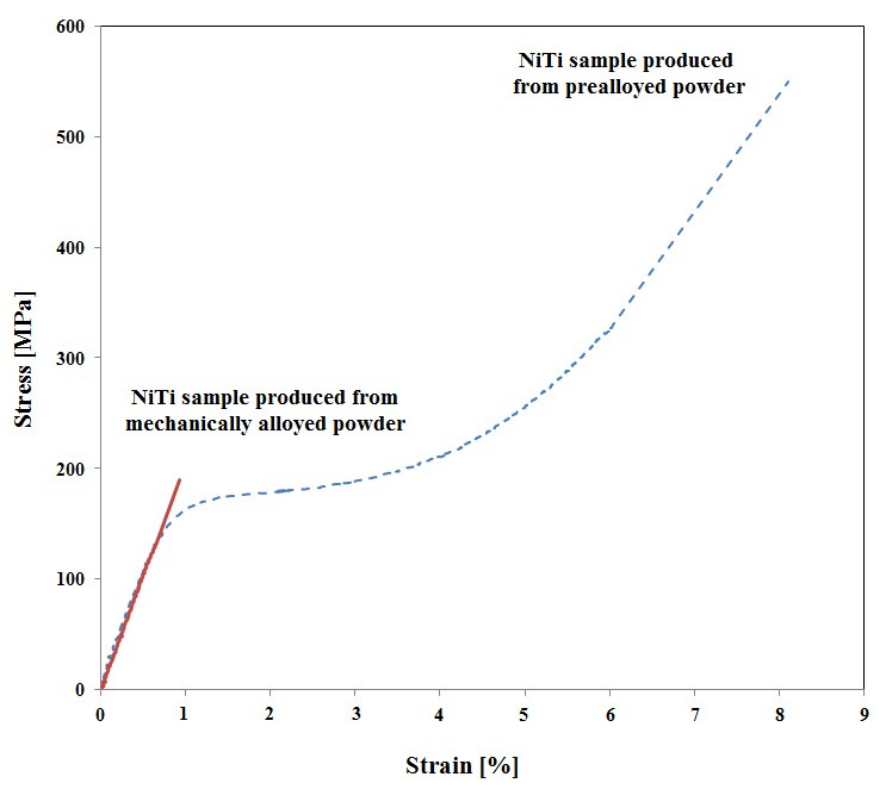

Fig. 6. Results of tensile tests performed on NiTi samples prepared from mechanically alloyed and prealloyed powders test and premature fracture occurred in this sample which is attributed to the existence of stable intermetallics in this sample. Also, the sample prepared from elemental powders did not show any plateau region which implies that this sample cannot exhibit PE or SME effects [17].

Fig. 7 and Table 1 shows results of nanoindentation tests conducted on $\mathrm{NiTi}_{2}$ and NiTi phases of sintered sample. It is seen that $\mathrm{NiTi}_{2}$ phase has a higher hardness and elastic modulus in compare with NiTi matrix but the $\eta$ ratio of this phase which is a measure of pseudoelasticity property is much lower than that in NiTi. With considering this issue, it is believed that formation of stable intermetallics in NiTi constrains the martensitic transformation and negatively affects its PE and SME properties.

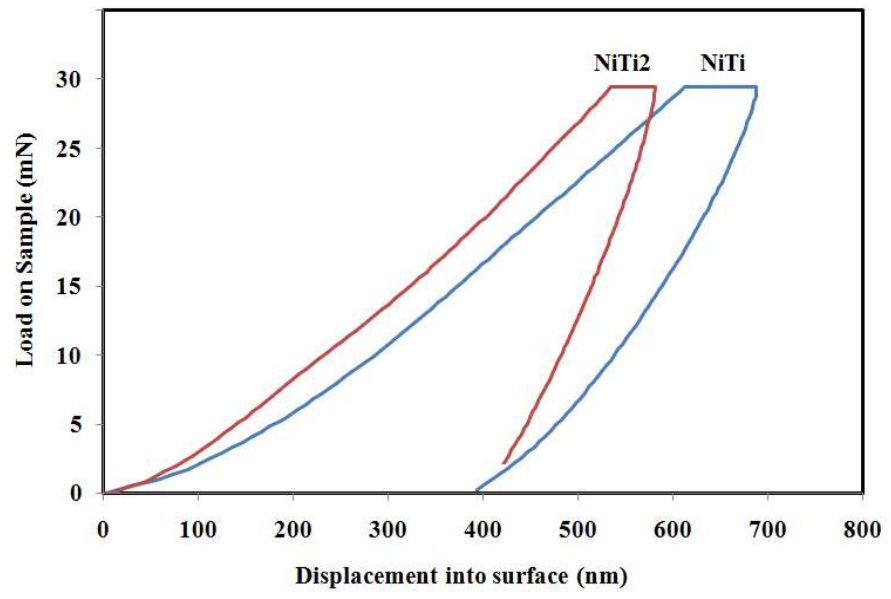

Fig. 7. Nanoindentation tests conducted on Ni-rich $\left(\mathrm{NiTi}_{2}\right)$ phase and NiTi matrix

TABLE 1

Results of local mechanical properties of $\mathrm{NiTi}$ and $\mathrm{NiTi}_{2}$ phases obtained from Fig. 7

\begin{tabular}{|c|c|c|c|}
\hline \hline Phase & $\begin{array}{c}\text { Nanohardness } \\
(\mathbf{G P a})\end{array}$ & $\begin{array}{c}\text { Elastic Modulus } \\
(\mathbf{G P a})\end{array}$ & $\begin{array}{c}\text { Pseudoelasticity } \\
(\boldsymbol{\eta} \text { ratio) } \%\end{array}$ \\
\hline $\mathrm{NiTi}$ & 3.9 & 55.2 & 44.5 \\
\hline $\mathrm{NiTi}_{2}$ & 5.1 & 97.1 & 29.1 \\
\hline
\end{tabular}

\section{Conclusions}

In this study, the challenges of using elemental nickel and titanium powders for production monolithic NiTi samples as a cost-effective method was investigated. The XRD results of samples consolidated with HIP process showed that in the microstructure of these samples stable intermetallics $\left(\mathrm{NiTi}_{2} / \mathrm{Ni}_{3} \mathrm{Ti}\right)$ coexists with NiTi phase. Formation of these intermetallics affects different aspects of NiTi. It alters the martensitic transformation temperatures, reduces the latent heat of martensitic transformation and restricts the detwinning and stress-induced martensite formation. Also, existence of $\mathrm{NiTi}_{2} / \mathrm{Ni}_{3}$ Ti phases improves hardness and elastic modulus but considerably deteriorates tensile properties of the sintered samples. 


\section{Acknowledgments}

This research work has been supported with research grant (No.: 247368) by Materials and EnergyResearch Center (MERC), Karaj, Iran.

\section{REFERENCES}

[1] J. Khalil-Allafi, B. Amin-Ahmadi, M. Zare, Mater. Sci. Eng. C 30, 1112-1117 (2010).

[2] M. Farvizi, T. Ebadzadeh, M.R. Vaezi, H.S. Kim, Mater. Des. 51C, 375-382 (2013).

[3] M.H. Elahinia, M. Hashemi, M. Tabesh, S.B. Bhaduri, Prog. Mater. Sci. 57, 911-946 (2012).

[4] K. Otsuka, X. Ren, Prog. Mater. Sci. 50, 511-678 (2005).

[5] M. Farvizi, T. Ebadzadeh, M.R. Vaezi, E.Y. Yoon, Y.J. Kim, H.S. Kim, A. Simchi, J. Alloy Comp. 606, 21-26 (2014).

[6] A. Cuniberti, S. Montecinos, F.C. Lovey, Intermetallics 17, 435440 (2009).
[7] B.T. Lester, T. Baxevanis, Y. Chemisky, D.C. Lagoudas, Acta Mech. 226 (12), 3907-3960 (2015).

[8] Y. Kaynak, Mater. Eng. Perform. 23, 3354-3360 (2014).

[9] M. Farvizi, T. Ebadzadeh, M.R. Vaezi, E.Y. Yoon, Y.J. Kim, J.Y. Kang, H.S. Kim, A. Simchi, Wear 334-335, 35-43 (2015).

[10] M. Farvizi, T. Ebadzadeh, M.R. Vaezi, A. Simchi, H.S. Kim, Nano 8, 1350048 (2013).

[11] L. Krone, E. Schüller, M. Bram, O. Hamed, H.P. Buchkremer, D. Stöver, Mater. Sci. Eng. A378, 185-190 (2004).

[12] R. Liu, D.Y. Li, Scr. Mater. 41, 691-696 (1999).

[13] C. Suryanarayana, Prog. Mater. Sci. 46 (1), 1-184 (2001).

[14] I. Barin, Thermochemical data of pure substances, Part I and II, VCH, Germany 1993.

[15] J.J.A. Laeng, Z. Xiu, X. Xu, X. Sun, H. Ru, Y. Liu, Physica Scripta, 129, 250-254 (2007).

[16] W. Tang, Metall. Mater. Trans. 28A, 537-544 (1997).

[17] M. Farvizi, M.R. Akbarpour, D.H. Ahn, H.S. Kim, J. Alloy Comp. 688, 803-807 (2016). 